\title{
Henri Wallon: psicologia e educação
}

\section{Resumo}

É propósito do presente trabalho apresentar uma reflexão sobre as contribuições da teoria de desenvolvimento e das idéias pedagógicas de Henri Wallon para a educação hoje. Para tanto, parte de uma análise dos conceitos fundamentais e princípios gerais da teoria e de seus pressupostos, e das principais idéias pedagógicas expressas em seus textos e no Projeto Langevin-Wallon. Ao considerar que Wallon atribui ao professor a função de mediar o acesso do aluno à cultura de seu tempo, e de cultivar nele aptidões compatíveis com as necessidades sociais, de forma que o ensino por ele ministrado seja uma preparação suficiente para o exercício de qualquer função que se poderia oferecer mais tarde, perguntamo-nos: que tipo de formação deveria ser oferecida aos professores de nosso tempo para que cumprissem esta função?

\section{Abstract}

It's purpose of the present article presenting for reflection on the contributions of the development theory and Henri Wallon's pedagogical ideas for the education nowadays. For this, it begins from an analysis of the fundamental concepts and the theory 'general principles and presuppositions, and the principal pedagogical ideas expressed in his texts and in Langevin-Wallon' Project. In considering that Wallon attributes to the teacher the function of mediating the access of the student to his time culture and him cultivate compatible aptitudes with the social needs, so that the teaching by himself ministered. Be a preparation for the exercise of any function that one could offer later, we ask: what kind of formation should be offered to the teachers of our time so that they can accomplish this function?

\section{Introdução}

Henri Wallon, além de elaborar uma teoria sobre o desenvolvimento humano, em virtude de sua preocupação com a educação, escreveu também sobre suas idéias pedagógicas apontando bases que a psicologia pode oferecer à atuação pedagógica e o uso que a pedagogia pode fazer dessas bases, além de se nutrir da experiência pedagógica.

Além dos textos voltados para a educação, Wallon expressou suas idéias pedagógicas também no Projeto Langevin-Wallon, um plano de reforma para o ensino da França que ele elaborou juntamente com o físico Paul Langevin, e que não chegou a ser implantado.

Apesar disso, a teoria de desenvolvimento de Wallon é ainda hoje pouco divulgada nos meios educacionais. Por acreditar que ela possa contribuir para a psicologia da educação, ou para a psicologia e para a educação, esperamos com o presente trabalho lançar algumas sementes, contribuindo para a construção de um espaço de interlocução para os, hoje ainda poucos, educadores wallonianos.

Psicogenética, essencialmente sociocultural e relativista, com forte lastro orgânico, a teoria de Wallon considera o desenvolvimento da pessoa completa integrada ao meio em que está imersa, com os seus aspectos afetivo, cognitivo e motor também integrados.

Assim, a ênfase é para a integração - entre organismo e meio e entre as dimensões: cognitiva,

\footnotetext{
*Doutoranda em Psicologia da Educação - PUC/SP. Coordenadora do Centro de Pós-Graduação, Pesquisa e Extensão das Faculdades Integradas "Campos Salles".

**Doutoranda em Psicologia da Educação - PUC/SP. Professora convidada do curso de Especialização em Psicopedagogia das Faculdades Integradas "Campos Salles".
} 
afetiva e motora na constituição da pessoa. A pessoa é vista como o conjunto funcional resultante da integração de suas dimensões, cujo desenvolvimento se dá na integração de seu aparato orgânico com o meio, predominantemente o social.

\section{O organismo em desenvolvimento na constituição da pessoa}

O desenvolvimento tem seu início na relação do organismo do bebê recém-nascido, essencialmente reflexos e movimentos impulsivos, também chamados descargas motoras, com o meio humano que as interpreta. Nesta fase distingue-se apenas estados de bem-estar ou desconforto. São as reações do ambiente humano, representado pela mãe, motivadas pela interpretação da mímica do bebê que permitem distinguir as emoções básicas. Essa mímica não é casual, mas um recurso biológico da espécie, essencialmente social, que faz do bebê um ser capaz de produzir, no ambiente humano, ainda representado pela mãe, um efeito mobilizador para sobreviver.

Desta forma é a dimensão motora que dá a condição inicial ao organismo para o desenvolvimento da dimensão afetiva.

A criança atua primeiro no ambiente humano, não no mundo físico. A mobilização do outro se faz pela emoção. É da protoconsciência, emocional, subjetiva que irá se desenvolver a consciência reflexiva. A vida psíquica é resultante do encontro da vida orgânica com o meio social.

Esse processo está ancorado no desenvolvimento neurológico, como sua condição e limite. A maturação orgânica é considerada condição para o desenvolvimento e permite descrevê-lo em estágios sucessivos e integrados. "A maturação orgânica é indispensável à evolução funcional".

Os primeiros meses de vida caracterizam-se por uma fusão total com o meio e pelo desenvolvimento rápido e completo dos automatismos emocionais responsáveis pela mobilização do meio humano para a satisfação das necessidades do bebê. Estes automatismos dependem de cen- tros nervosos especiais e aparecem na criança como fato de maturação.

O desenvolvimento das funções depende tanto de condições de maturação como de exercícios capazes de desenvolvê-las, portanto condições do meio. No estágio sensório-motor, a criança realiza um extenso e diferenciado acordo entre as percepções e os movimentos. Esta relação em sua forma mais simples é o ato reflexo, ou seja, a uma determinada excitação corresponde um determinado movimento. Com a maturação neurológica, os reflexos são inibidos e a criança se torna capaz de realizar exercícios sensório-motores que conduzem a um duplo resultado: ligar o efeito perceptível aos movimentos próprios para produzi-los, e diversificar os movimentos e os efeitos possíveis. Coordenando mutuamente os campos sensorial e motor, completa-se o arranjo funcional da atividade conforme as suas atividades objetivas.

É a ação motriz que regula o aparecimento e o desenvolvimento das funções mentais. $\bigcirc$ movimento espontâneo transforma-se aos poucos em gesto, que, ao ser realizado a partir de uma intenção, se reveste de significação ligada à ação, voltada para a realização da cena, fora da qual nada significa.

O desenvolvimento das funções psicológicas superiores se dá, portanto, a partir do desenvolvimento das dimensões motora e afetiva. É a comunicação emocional que dá acesso ao mundo adulto, ao universo das representações coletivas. A inteligência surge depois da afetividade, e a partir das condições de desenvolvimento motor, se alterna e conflita com ela.

A cognição é vista como parte da pessoa completa que só pode ser compreendida integrada a ela, cujo desenvolvimento se dá a partir das condições orgânicas da espécie, e é resultante da integração entre seu organismo e o meio, predominantemente o social. Assim, o desenvolvimento é condicionado tanto pela maturação orgânica, como pelo exercício funcional, propiciado pelo meio. Segundo Wallon (1979):

"O que permite à inteligência essa transferência do plano motor para o plano especulativo não é evi- 
dentemente explicável no desenvolvimento do indivíduo (...) mas nele pode ser identificada [a transferência] (...) são as aptidões da espécie que estão em jogo, em especial as que fazem do homem um ser essencialmente social". (p.131)

A evolução da espécie humana fez do homem um ser geneticamente social, desenvolvendo nele aptidões específicas. A função simbólica é a aptidão específica da espécie humana que se refere ao poder de encontrar, para um objeto, a sua representação e, para esta representação, um signo. $\bigcirc$ desenvolvimento deste potencial pela espécie tem na sua base a vida em sociedade que pressupõe objetivos comuns e necessidade de comunicação. Assim, o desenvolvimento da inteligência se processa em um organismo a priori capaz disso, dependendo para tanto de seu encontro com o meio social.

Partes da pessoa completa, as funções psicológicas superiores, que se desenvolvem a partir de exercícios funcionais motores, serão mais tarde nutridas da sua inibição e não de sua estimulação. $\mathrm{O}$ movimento que se encontra na gênese da representação e a acompanha durante sua evolução inicial, termina por ser inibido por ela, condição necessária ao desenvolvimento das funções mentais específicas da representação pura.

O desenvolvimento não se dá de maneira linear e contínua, mas por integração de novas funções e aquisições às anteriores. A acumulação quantitativa de funções culmina na evolução qualitativa das mesmas a partir de uma nova organização em que as dimensões motora, afetiva e cognitiva se integram de maneira diversa da fase anterior, alternando-se no exercício de predominância de uma sobre as demais. A preponderância de um dos aspectos sobre os demais é decorrente da sua integração, que é plástica, dinâmica e resultante da superação da oposição de um em relação aos outros.

Uma visão de conjunto, em que as dimensões da pessoa se integram de forma dinâmica, alternando-se em relação à predominância de uma frente às demais, é necessária para a compreensão da concepção de desenvolvimento walloniana. A integração não é um estado alcançado ao final de um processo, mas define a condição plástica, o equilíbrio dinâmico da pessoa em desenvolvimento.

Wallon admite a existência de três leis que regulam o processo de desenvolvimento da criança em direção ao adulto: a lei da alternância funcional, a da preponderância funcional e a da integração funcional.

A primeira, chamada lei da alternância funcional, indica duas direções opostas que se alternam ao longo do desenvolvimento: uma centrípeta, voltada para a construção do eu e a outra centrífuga, voltada para a elaboração da realidade externa e do universo que a rodeia. Essas duas direções se manifestam alternadamente, constituindo o ciclo da atividade funcional.

A segunda é a lei da sucessão da preponderância funcional, na qual as três dimensões ou subconjuntos preponderam, alternadamente, ao longo do desenvolvimento do homem: motora, afetiva e cognitiva. A função motora predomina nos primeiros meses de vida da criança, enquanto as funções afetiva e cognitiva se alternam ao longo de todo o desenvolvimento, ora visando à formação do eu (predominância afetiva), ora visando ao conhecimento do mundo exterior (predominância cognitiva).

A última lei, chamada de lei da diferenciação e integração funcional, diz respeito às novas possibilidades que não se suprimem ou se sobrepõem às conquistas dos estágios anteriores, mas, pelo contrário, integram-se a elas no estágio subseqüente.

A integração dos três subconjuntos funcionais - motor, afetivo e cognitivo - constitui o último e quarto subconjunto funcional, denominado por Wallon pessoa. Para Wallon, em qualquer momento, ou fase do desenvolvimento, a pessoa é sempre uma pessoa completa.

Outra tendência apontada por Wallon, manifesta no desenvolvimento da pessoa completa, é a de caminhar do sincretismo em direção à diferenciação. Movimentos, sentimentos e idéias são a princípio vividos de maneira global, até mesmo confusa, quando a pessoa não tem clareza da situação. Aos poucos, tornam-se mais claros e 
adequados às necessidades que a situação apresenta. Sobre esta questão, nos diz Mahoney (2000): "Desenvolver-se é ser capaz de responder com reações cada vez mais específicas a situações cada vez mais variadas". (p. 14)

A Teoria das Emoções é de grande importância na obra de Wallon. Segundo o autor, a emoção é a exteriorização da afetividade, um fato fisiológico nos seus componentes humorais e motores e, ao mesmo tempo, um comportamento social na sua função de adaptação do ser humano ao seu meio:

“...As emoções são a exteriorização da afetividade(....) Nelas que assentam os exercícios gregários, que são uma forma primitiva de comunhão e de comunidade. As relações que elas tornam possíveis afinam os seus meios de expressão, e fazem deles instrumentos de sociabilidade cada vez mais especializados". (Wallon, 1995, p. 143)

A emoção, antes da linguagem, é o meio utilizado pelo recém-nascido para estabelecer uma relação com o mundo humano. Gradativamente, os movimentos de expressão, primeiramente fisiológica, evoluem até se tornarem comportamentos afetivos mais complexos, nos quais a emoção, aos poucos, cede terreno aos sentimentos e depois às atividades intelectuais.

As emoções são instantâneas e diretas e podem expressar-se como verdadeiras descargas de energia. Quando isto ocorre, elas têm o poder de se sobrepor ao raciocínio e ao conhecimento.

A afetividade evolui conforme as condições maturacionais de cada pessoa e com formas de expressões diferenciadas, que se configuram como um conjunto de significados que o indivíduo adquire nas relações com o meio, com a cultura, ao longo da vida. Os significados representam para cada pessoa as diferentes situações e experiências vivenciadas num determinado momento e ambiente social. Por este motivo, afetividade não permanece imutável ao longo da trajetória da pessoa.

A afetividade corresponde à energia que mobiliza o ser em direção ao ato, enquanto a in- teligência corresponde ao poder estruturante que o modela a partir dos esquemas disponíveis naquele momento.

Para Wallon, a emoção precede nitidamente o aparecimento das condutas do tipo cognitivo e é um processo corporal que, quando intenso, pode impulsionar a consciência a se voltar para as alterações proprioceptivas, prejudicando a percepção do exterior. Em virtude de seu poder de sobrepor-se à preponderância da razão, é necessário, segundo Wallon, manter-se uma "baixa temperatura emocional”, para que se possa trabalhar as funções cognitivas.

A emoção é capaz de preponderar sobre a razão sempre que à última faltem recursos para controlar a primeira. $\mathrm{O}$ desenvolvimento deve conduzir à predominância da razão, pois, para Wallon, "a razão é o destino final do homem".

A integração entre as dimensões motora, afetiva e cognitiva, conceito central da teoria de Wallon, é claramente descrito por Mahoney (2000):

"O motor, o afetivo, o cognitivo, a pessoa, embora cada um desses aspectos tenha identidade estrutural e funcional diferenciada, estão tão integrados que cada um é parte constitutiva dos outros. Sua separação se faz necessária apenas para a descrição do processo. Uma das conseqüências dessa interpretação é de que qualquer atividade humana sempre interfere em todos eles. Qualquer atividade motora tem ressonâncias afetivas e cognitivas; toda disposição afetiva tem ressonâncias motoras e cognitivas; toda operação mental tem ressonâncias afetivas e motoras. E todas essas ressonâncias têm um impacto no quarto conjunto: a pessoa". (p. 15)

\section{O papel do meio na constituição da pessoa}

O conceito de meio é fundamental na teoria walloniana. Nela, como já foi acima referido, a pessoa constitui-se na integração de seu organismo com o meio, estando o social sobreposto ao natural. As atitudes da pessoa são consideradas complementares às do meio, tanto quanto deter- 
minadas pelas suas disposições individuais e pelo papel e lugar que ocupa no grupo social. Portanto, a pessoa deve ser vista integrada ao meio do qual é parte constitutiva e no qual, ao mesmo tempo, se constitui. A este respeito nos diz Wallon (1975):

"Sem dúvida que o papel e o lugar que aí ocupa [a criança] são em parte determinados pelas suas próprias disposições, mas a existência do grupo e as suas exigências não se impõem menos à sua conduta. Na natureza do grupo, se os elementos mudam, as suas reações mudam também”. (p.20)

A constituição da pessoa se dá de acordo com suas condições de existência. $\mathrm{O}$ meio social e a cultura constituem as condições, as possibilidades e os limites de desenvolvimento para o organismo.

Durante a primeira etapa, denominada por Wallon de Estágio Impulsivo, os atos da criança têm o objetivo de chamar a atenção do adulto por meio de gestos, gritos e expressões, para que ele satisfaça as suas necessidades e garanta assim a sua sobrevivência.

Durante o desenvolvimento, a simbiose respiratória do feto se transforma em simbiose alimentar no recém-nascido e, por volta dos três meses, em simbiose afetiva, característica específica da espécie humana. A esta fase Wallon chama de Estágio Emocional.

A criança aos poucos aprende a contagiar o adulto com sorrisos e sinais de contentamento, o que caracteriza laços de caráter afetivo com aqueles que estão a sua volta, e demonstra necessidade de manifestações afetivas, necessidade que precisa ser atendida para que tenha um desenvolvimento satisfatório.

Para que a humanidade possa sobreviver, é necessário que a imperícia do recém-nascido afete o outro e provoque nele sentimentos de solidariedade: é a garantia de sobrevivência da espécie. Este, para Wallon, é o maior indicador de que o meio social é privilegiado para a criança em desenvolvimento e para o homem adulto, em relação ao meio físico.

A criança, que está primeiramente ligada à mãe, aos poucos diferencia outras pessoas que desempenham papéis significativos em relação a ela, como, por exemplo, pai, avós, tios e padrinhos. Sua sociabilidade se amplia rapidamente quando começa a andar e a falar. Andando, a criança pode interagir mais com o ambiente que a cerca. A aquisição da linguagem possibilita-lhe ao nomear objetos e pessoas, diferenciá-los.

Nesta etapa, denominada por Wallon de Estágio Sensório-Motor, a criança aprende a conhecer os outros como pessoas em oposição à sua própria existência.

É o tempo dos jogos espontâneos de alternância, do interesse por atos que unem duas pessoas ou, principalmente, papéis diferentes, como, por exemplo, o jogo de dar e receber tapinhas, de esconder e ser escondido pela almofada etc.

Esses jogos alargam o horizonte e a vivência da criança, pois fazem com que ela conceba relações mais ricas. Nesse período, a criança ainda está estreitamente dependente do outro, pois seu processo de individuação está apenas se iniciando. Ela ainda vive sua relação com o outro de maneira bastante sincrética, sem se diferenciar claramente dele.

É somente no Estágio do Personalismo, que vai dos três aos cinco anos, que a criança realmente se diferencia do outro, toma consciência de sua autonomia em relação aos demais. Ela percebe as relações e os papéis diferentes dentro do universo familiar, ao mesmo tempo que se percebe como um elemento fixo, como ser o filho mais velho ou o mais novo, ser filho e irmão, assim por diante.

Nessa idade, a criança também costuma ingressar na escola maternal, inserindo-se numa comunidade de crianças semelhantes a ela, onde as relações serão diferentes das relações familiares. As necessidades dessa faixa etária ainda exigem do professor cuidados de caráter pessoal, diretos, quase como os de mãe.

$\mathrm{Na}$ etapa seguinte, denominada Categorial, idade de escolaridade obrigatória na maioria dos países, o desenvolvimento cognitivo da criança está aguçado e a sua sociabilidade ampliada. A criança se vê capaz de participar de vários grupos 
com graus e classificações diferentes, segundo as atividades de que participa. Esta etapa é importante para o desenvolvimento das aptidões intelectuais e sociais da criança.

Vivenciar a necessidade de se perceber como indivíduo, e, ao mesmo tempo, de medir sua força em relação ao grupo social a que pertence, faz desta fase um período crítico do processo de socialização, pois, segundo Wallon (1975):

"Há tomada de consciência pelo indivíduo do grupo de que faz parte, há tomada de consciência pelo grupo da importância que pode ter em relação aos indivíduos". (p.215)

A adolescência, que para Wallon tem início aos 12 anos com a puberdade, é marcada por transformações de ordem fisiológica, mudanças corporais impostas pelo amadurecimento sexual, assim como transformações de ordem psíquica com preponderância afetiva.

Nesse estágio, os sentimentos se alternam procurando buscar a consciência de si na figura do outro, contrapondo-se a ele, além de incorporar uma nova percepção temporal.

meio social e cultural passam a ser de grande importância. Os adolescentes tornam-se intolerantes em relação às regras e ao controle exercido pelos pais, e necessitam identificar-se com seu grupo de amigos.

$\mathrm{Na}$ adolescência torna-se bastante visível a forma como o meio social condiciona a existência da pessoa, configurando-se a personalidade de maneiras diversas. Enquanto os adolescentes de classe média exteriorizam seus sentimentos e questionam valores e padrões morais, os de classes operárias, que enfrentam precocemente a realidade social do adulto, a necessidade de trabalho, vivem essa fase de outra maneira, pois têm de contribuir para a subsistência da família.

Para Wallon, o processo de socialização da pessoa não se dá apenas no seu contato com o outro nas diversas etapas do desenvolvimento e da vida adulta, mas também no contato com a produção do outro. $\mathrm{O}$ encontro com o texto, com a pintura ou com a música produzida pelo outro, propicia a identificação como homem genérico e, ao mesmo tempo, a diferenciação como homem concreto, o que contribui ao processo de individuação e constituição do eu. É por isso que, segundo Wallon, a cultura geral aproxima os homens, à medida que permite a identificação de uns com outros, enquanto a cultura específica e o conhecimento técnico os afastam, ao individualizá-los e diferenciá-los.

A cultura é, para Wallon, ao mesmo tempo, fator constituinte da pessoa e representante das aptidões totais do homem genérico, à medida que é constituída pela totalidade dos homens de determinada época e lugar.

\section{Contribuições da teoria à Educação}

Wallon chama de humanismo ampliado a concepção que implica a plena realização do homem em cada indivíduo. O homem completo só é concebido em sua forma universal atribuindo-lhe o poder de compreender, ponderar e escolher.

Uma educação humanista, segundo Wallon, deve considerar todas as disposições que constituem o homem completo, mesmo estando desigualmente repartidas entre os indivíduos, pois qualquer indivíduo potencialmente pode se desenvolver em qualquer direção, a depender de seu aparato biológico e das condições em que vive.

Segundo Wallon, uma aptidão só se manifesta se encontrar ocasião favorável e objetos que lhes respondam. Muitas aptidões novas poderiam manifestar-se no encontro das necessidades psicológicas das crianças e as necessidades crescentes da sociedade.

Assim, o acesso à cultura é função primordial da educação formal, pois ela é a expressão do florescimento das criações e das aptidões do homem genérico, universal, sejam manuais, corporais, estéticas, intelectuais ou morais. A escola é parte das condições de existência na qual a pessoa se desenvolve e constitui, devendo intervir neste processo de maneira a promover o desenvolvimento de tantas aptidões quantas forem possíveis.

O Projeto Langevin-Wallon propunha uma educação integral do pré-escolar até a universi- 
dade e tinha na sua gênese a preocupação com a formação dos valores éticos e morais, pois considerava a escola um espaço social adequado para tal. Visando a uma educação preocupada com a formação geral sólida, para a autonomia, a cidadania e a orientação profissional, fundamentadas pelos princípios de justiça, igualdade e respeito à diversidade, o projeto sistematizou e sugeriu etapas consecutivas que priorizassem aspectos e necessidades específicas de cada faixa etária, respeitando o desenvolvimento afetivo, cognitivo de socialização e maturação biológica de cada indivíduo.

Os programas educacionais deveriam ser reformados de maneira que toda aptidão pudesse ser orientada, cultivada segundo sua natureza, de forma que o ensino recebido fosse uma preparação suficiente para o exercício de qualquer função que se poderia oferecer mais tarde.

Wallon acreditava que as aptidões eram cultivadas, desenvolvidas em contato com a cultura, e não inatas, embora elas dependam também de condições orgânicas. Por isso atribuiu à escola, como função primordial, dar acesso a cultura visando ao cultivo das aptidões, pois só podem exercer as disposições que constituem o homem completo - compreender, ponderar e escolher aqueles aos quais for dado a conhecer a cultura de seu tempo.

Wallon acreditava que todos deveriam ter oportunidades iguais, inclusive ao respeito à singularidade, e para isso seria necessário haver escola para todos, na qual cada um pudesse encontrar, segundo suas aptidões, todo o desenvolvimento intelectual, estético e moral que fosse capaz de assimilar. Oferecida uma base comum, dever-se-ia também propiciar condições para que a criança, experimentando, descobrisse suas tendências de acordo com seu estágio de desenvolvimento:

- dos três aos onze anos, as aptidões parecem não contribuir de maneira eficiente. Exatamente por este motivo, o momento seria propício, segundo Wallon, para orientar e cultivar todas elas, cada uma de acordo com sua natureza: manual, corporal, estética, intelectual e moral.
- entre onze e quinze anos, sobre um fundo de aquisições comuns, emergem aptidões mais particulares, mais pessoais, mais originais que devem encontrar tarefas que ajudem no desenvolvimento. A oferta de alternativas deveria ser ampla o suficiente para permitir à criança, ao exercitar e desenvolver novas funções, reconhecer suas preferências e suas dificuldades.

- à universidade caberia a formação profissional, a investigação científica e a difusão da cultura, associando uma cultura geral superior a uma especialização muito avançada.

Wallon afirma que o meio e a cultura condicionam os valores morais e sociais que a criança incorporará, e que devem ser cultivados os valores de solidariedade e justiça. Insiste na importância de o professor conhecer as condições de existência de seu aluno, para saber quais os valores que nela estão sendo cultivados, nos outros meios em que está imersa, e saber como cultivar aqueles que são seu objetivo.

A partir de sete anos, a criança vive, ao mesmo tempo, sentimentos e situações de cooperação, exclusão e rivalidade. Caberia ao professor intervir, propondo atividades que privilegiassem trabalhos em grupo e atitudes de cooperação, em relação aos trabalhos individuais, uma vez que, nessa época, podem acirrar-se rivalidades em detrimento da solidariedade. Além disso, o momento é propício para preparar a criança para a etapa seguinte que é a adolescência.

Diante do adolescente, compreendendo as características de seu estágio de desenvolvimento, o professor pode atuar no sentido de ajudá-lo a distinguir valores sociais e morais.

A responsabilidade é um dos sentimentos que o educador deve buscar promover no adolescente, uma vez que ela tem ingredientes capazes de mobilizar essa faixa etária graças as suas características específicas, pois responsabilidade representa, segundo Wallon (1975):

"Tomar a seu cargo o êxito de uma ação que é executada em colaboração com outros ou em proveito de uma coletividade. A responsabilidade confere um direito de domínio por uma causa, mas também um 
dever de sacrifício, o que significa que o adolescente responsável é aquele que deve se sacrificar mais por tarefas sociais que contribuem para o crescimento e desenvolvimento da coletividade e do grupo". (p. 222)

O professor pode, desta forma, auxiliar o adolescente em suas indecisões e angústias, propondo atividades que propiciem o reconhecimento de suas tendências e o cultivo de aptidões orientando a proposição de metas e objetivos futuros.

\section{Considerações finais}

Com certeza, a tarefa de educar demanda posturas e conhecimentos diferenciados da parte do professor, pois ele desempenha o papel de mediador do processo escolar de aquisição da cultura pelo aluno, e, portanto, de cultivador de aptidóes. Desta forma, apresenta-se-nos uma tarefa complexa, que requer habilidades e conhecimentos específicos, autoconhecimento e conhecimento do universo social do professor e do aluno, para aí então tomar decisões comprometidas com a constituição da pessoa do aluno.

O conhecimento do desenvolvimento do aluno, das necessidades específicas de cada etapa, deve pautar a prática pedagógica, que é uma intervenção nesse processo em determinada direção, a ser feita de maneira consciente e responsável, em consonância com valores morais e sociais, objetivos e metas educacionais.

Falar sobre infância e adolescência representa, de início, uma dificuldade, por serem elas, antes de mais nada, construções culturais, situadas, datadas, cujas contraposições com o universo do adulto podem ser diversificadas.

Para compreendermos a criança e o adolescente de hoje, é útil compreendermos como esses conceitos, desde a sua origem, evoluíram através dos tempos, chegando até nós. Necessário também é procurar conhecer e compreender em que circunstâncias o referencial teórico que norteia o nosso olhar foi produzido, para, ao analisá-lo, sermos capazes de verificar o que precisa ser revisto e readaptado em função de condições existenciais distintas daquelas em que a teoria foi produzida.
Além disso, faz-se ainda necessário termos clareza dos pressupostos que norteiam a nossa visão de criança e adolescente constituída ao longo de nossa trajetória pessoal, como pessoas e sujeitos históricos. Conhecer esses pressupostos, a princípio, é tornar-se capaz de redimensioná-los para maior adequação à realidade objetiva e às nossas metas e objetivos como professores e, portanto, interventores no processo de desenvolvimento de nossos alunos.

As novas gerações levantam a necessidade de outra avaliação das relações interpessoais e da relação com o conhecimento. Há necessidade de pesquisas capazes de proporcionar uma melhor compreensão dessas relações, gerando bases para novas práticas pedagógicas.

Costumamos ouvir dos professores discursos sobre a importância de formarmos alunos conscientes, cujos valores éticos e morais lhes possibilitem exercer o papel de cidadãos. Mas, como fazê-lo?

Acreditamos que a teoria de Wallon, por seu forte lastro orgânico, o que a ancora nas aptidões características da espécie, e por sua essência sociocultural relativista, é capaz de contribuir para a compreensão do desenvolvimento das crianças e dos adolescentes de nossos tempos e cultura, ao mesmo tempo em que suas idéias pedagógicas nos parecem bastante adequadas ao tipo de escola capaz de atender aos interesses e necessidades de nossos alunos da era digital.

Uma reflexão extremamente relevante sobre as implicações da teoria de Wallon para a educação, especificamente sobre o papel do professor, nos é apresentada por Almeida (2000):

"Wallon, psicólogo e educador, legou-nos muitas outras lições. A nós, professores, duas são particularmente importantes. Somos pessoas completas: com afeto, cognição e movimento, e nos relacionamos com um aluno, também pessoa completa, integral, com afeto, cognição e movimento. Somos componentes privilegiados do meio de nosso aluno". (p.86)

Conseqüência da presente interpretação da teoria e princípios wallonianos, é a concepção do 
professor como pessoa completa e de seu papel como mediador da cultura de seu tempo e, portanto, um cultivador das novas aptidões possibilitadas por ela.

Impõe-se-nos desta forma uma importante questão: estaremos nós preparados para sermos mediadores da cultura digital? Temos nós próprios, professores-pessoas, desenvolvidas as aptidões próprias desta cultura? Estamos aptos a exercer nosso papel como interventores no processo de desenvolvimento de nossos alunos no sentido de promover a aquisição de conhecimentos e valores adequados à formação do cidadão desta nova era?

Que tipo de formação deve ser propiciada à pessoa do professor, para que, em seu encontro com a pessoa do aluno, seja capaz de desempenhar bem o seu papel de mediador da cultura de seu tempo, que chamamos aqui de cultura digital, cultivando nele aptidões compatíveis com ela, de forma que o ensino ministrado por ele seja uma preparação suficiente para o exercício de qualquer função que se poderá oferecer mais tarde?

Temos pela frente ainda um longo caminho a percorrer até que sejamos capazes de dar alguma resposta a esta pergunta, mas acreditamos que para fazê-lo é necessário investir na formação da pessoa do professor, principalmente na formação contínua, considerando a sua experiência na escola, diante do aluno, lugar em que se constitui professor. A este respeito nos diz Wallon (1975):

"A formação psicológica dos professores não pode ficar limitada aos livros. Deve ter referência perpétua nas experiências pedagógicas que eles próprios podem pessoalmente realizar". (p.366)

\section{REFERÊNCIAS BIBLIOGRÁFICAS}

ALMEIDA, Laurinda Ramalho de. Wallon e a Educação. In: Henri Wallon: Psicologia e educação. São Paulo: Loyola, 2000. MAHONEY, Abigail Alvarenga. Introdução. In: Henri Wallon: Psicologia e educação. São Paulo: Loyola, 2000.

WALLON, Henri. Psicologia e educação da infância. Lisboa: Estampa, 1975.

. Do acto ao pensamento. Lisboa: Moraes, 1979. 